\title{
CORRECTION
}

\section{Correction to: Outcomes of double stratification in Darcy-Forchheimer MHD flow of viscoelastic nanofluid}

\author{
T. Hayat ${ }^{1,2} \cdot$ F. Shah ${ }^{1} \cdot$ Zakir Hussain $^{1} \cdot$ A. Alsaedi ${ }^{2}$
}

Published online: 24 December 2019

(c) The Brazilian Society of Mechanical Sciences and Engineering 2019

\section{Correction to: Journal of the Brazilian Society of Mechanical Sciences and Engineering (2018) 40:145 https://doi.org/10.1007/s40430-018-0973-3}

In the published version of original article, the energy equation (3) is incorrect. The correct form of Eq. (3) is as follows:

$$
\begin{aligned}
u \frac{\partial T}{\partial x}+v \frac{\partial T}{\partial y}= & \tau\left(D_{B} \frac{\partial C}{\partial y} \frac{\partial T}{\partial y}+\frac{D_{T}}{T_{\infty}}\left(\frac{\partial T}{\partial y}\right)^{2}\right) \\
& +\frac{Q(x)\left(T-T_{\infty}\right)}{\rho c_{p}}+\frac{\partial}{\partial y}\left(\alpha^{*}+\frac{16 \sigma^{*} T_{\infty}^{3}}{3 k k^{*}}\right) \frac{\partial T}{\partial y}
\end{aligned}
$$

Note that, this correction is only for the equation and does not affect the results presented in the original paper. The corresponding parameter after equation 20 is corrected by replacing "k" by" $\mathrm{k} *$ "

$R_{d}=\frac{16 \sigma^{*} T_{\infty}^{3}}{3 k k^{*}}$

Publisher's Note Springer Nature remains neutral with regard to jurisdictional claims in published maps and institutional affiliations.
The original article can be found online at https://doi.org/10.1007/ s40430-018-0973-3.

\section{Zakir Hussain}

zakir.qamar@yahoo.com

1 Department of Mathematics, Quaid-I-Azam University, 45320, Islamabad 44000, Pakistan

2 Nonlinear Analysis and Applied Mathematics (NAAM), Research Group, Department of Mathematics, Faculty of Science, King Abdulaziz University, P.O. Box 80257, Jeddah 21589, Saudi Arabia 